\title{
The effects of argon ion bombardment on the corrosion resistance of tantalum
}

\author{
A. H. Ramezani ${ }^{1}$ A. H. Sari ${ }^{2}$ A. Shokouhy ${ }^{2}$
}

Received: 22 October 2016/ Accepted: 1 February 2017/Published online: 17 February 2017

(C) The Author(s) 2017. This article is published with open access at Springerlink.com

\begin{abstract}
Application of ion beam has been widely used as a surface modification method to improve surface properties. This paper investigates the effect of argon ion implantation on surface structure as well as resistance against tantalum corrosion. In this experiment, argon ions with energy of $30 \mathrm{keV}$ and in doses of $1 \times 10^{17}$ $10 \times 10^{17}$ ions $/ \mathrm{cm}^{2}$ were used. The surface bombardment with inert gases mainly produces modified topography and morphology of the surface. Atomic Force Microscopy was also used to patterned the roughness variations prior to and after the implantation phase. Additionally, the corrosion investigation apparatus wear was applied to compare resistance against tantalum corrosion both before and after ion implantation. The results show that argon ion implantation has a substantial impact on increasing resistance against tantalum corrosion. After the corrosion test, scanning electron microscopy (SEM) analyzed the samples' surface morphologies. In addition, the elemental composition is characterized by energy-dispersive X-ray (EDX) analysis. The purpose of this paper was to obtain the perfect condition for the formation of tantalum corrosion resistance. In order to evaluate the effect of the ion implantation on the corrosion behavior, potentiodynamic tests were performed. The results show that the corrosion resistance of the samples strongly depends on the implantation doses.
\end{abstract}

A. H. Ramezani

ramezani.1972@gmail.com

1 Department of Physics, West Tehran Branch, Islamic Azad University, Tehran, Iran

2 Plasma Physics Research Center, Science and Research Branch, Islamic Azad University, Tehran, Iran
Keyword Argon - Bombardment - Tantalum · AFM . SEM $\cdot$ Corrosion

\section{Introduction}

Tantalum (Ta) is one of the most important metallic biomaterials and often applied as film material to improve the performance of substrate because of its excellent biocompatibility and high corrosion resistance. The combination of physical and chemical properties of tantalum makes it a unique material for using in high temperature and advanced technological applications. Some exceptional properties of tantalum are high melting point, good heat and electrical conductivity, corrosion resistance and high ductility. Tantalum crucibles are used for high-temperature processes, like fusion, thin-film deposition, distillation, and as heat exchangers. In the electronic industry, tantalum is used for manufacturing of capacitors, coils and boats for resistive evaporation. In the recent years, thin films of tantalum are attractive in a number of applications, which include protective coatings for corrosion, and wear resistance [1-4] because of its very high melting point, toughness, and immunity to chemical attack. The inertness of Tantalum in contact with body fluids and tissues, and excellent his tocompatibility makes it useful in biomedical implants and orthopedics [5].

Today, the application of ion beam is considered as one of the effective approaches to improve the metal properties since ion implantation can change the surface morphology, which causes some microstructure defects and modifies the corrosion resistance [8]. Ion implantation using active gases are not so common to produce structure change and do some topographical and morphological changes and 
introduce chemical change on the surface of the sample $[7,8]$.

Wear control and corrosion were among the first applications observed because of the large economic burden they impose on society. A large number of survey experiments with some successes, some failures, and some contradictory results characterized early results. The basic framework for understanding corrosion phenomena is the mixed potential theory of corrosion [1]. Corrosion reactions in aqueous media are oxidation-reduction reactions in which the free energy change determines the feasibility of the reaction and iscontrolled by electrode kinetics. These reasons can be combined on electrode potential versus current density diagrams to describe corrosion reactions and their anodic and cathodic partial reactions. The use of ion bombardment to control corrosion includes modification of the surface composition to manipulate either the anodic or the cathodic reaction in a way, which reduces the corrosion current.

During the past 15 years, it has been observed that in addition to argon ion implantation, other ions, such as tantalum, chromium, boron and carbon, are needed to optimize the effects of ion implantation on the tribological and corrosive behavior of materials. In other words, ion implanters for surface modification of metals can be made a suitable substrate in different applications due to change of surface such as capacitors, resistors, and more recently as diffusion barriers in integrated circuits with copper interconnects [6-9], and polish stop in chemical mechanical polishing [10]. Other applications of Ta are in X-ray optics and in X-ray lithography as absorbers [11]. The ability to change metal surfaces with ion implantation has afforded the corrosion researcher a new flexibility in trying to recover the corrosion resistance of metals. At the Naval Research Laboratory, for example, there has been an extensive program aimed at improving corrosion resistance using the techniques of ion bombardment, ion beam mixing, and ion beam-assisted deposition, as well as laser surface processing and alloying [12].

It is well known that aqueous corrosion proceeds through the operation of microscopic coupled anodic and cathodic processes. Thus, ion implantation modification can be utilized so as to interfere with the corrosion process by (1) modification of the cathodic process or (2) modification of the anodic process Other approaches involve (3) use of corrosion-resistant coatings, and (4) improvement of the passive film [13-17].

In this study, tantalum was applied as substrate for doing argon ion implantation in various doses to investigate the change of surface roughness, corrosion resistance, and the effects of corrosion on the surface by using atomic force microscopy and scanning electron microscopy.

\section{Experimental details}

Ion bombardment was carried out on tantalum samples with size of $1 \mathrm{~cm} \times 1 \mathrm{~cm}$ and $1 \mathrm{~mm}$ thicknesses by the ion implantation facility, which was performed in Plasma Physics Research Center (PPRC), Science and Research Branch. Table 1 shows the chemical composition of the substrates, analyzed by Energy Dispersive X-ray (EDX). Fig. 1 shows the schematic of ion implantation system. Ion bombardment procedure is performed by argon ions (99.999\%) with the energy of $30 \mathrm{keV}$ and doses of $1 \times 10^{17}-10 \times 10^{17}$ ions $/ \mathrm{cm}^{2}$ at ambient temperature and the angle between the implanted ions and surface of samples is $90^{\circ}$. Before ion implantation, sample surfaces were polished to a glossy finish by diamond paste and then cleaned ultrasonically in alcohol and acetone bath and then dried in an oven at $100{ }^{\circ} \mathrm{C}$. The extracted ions (without mass selection) are accelerated to the maximum energy of $30 \mathrm{keV}$. Ion beam energy and current densities are kept fixed for all the samples. The ion beam cross section was expected to cover all the sample area uniformly. A thermocouple is used to measure the sample temperature during the implantation. The implantation parameters are listed in Table 2. Before starting of ion implantation, the entire sample had room temperature. This temperature changed during implantation because of heat transfer from ion bombardment to the samples.

The structural properties and composition of the tantalum samples are investigated with different methods. The implantation-induced modification of surface roughness is studied employing an atomic force microscopy (AFM). SPM Auto Probe CP, Park Scientific Instruments to investigate the morphology and roughness of the surface, performed atomic force microscopy (AFM). AFM was carried out in a non-contact mode and in the scanning area of $1 \mu \mathrm{m}^{2}$ with a low stress tip of less than $20 \mathrm{~nm}$ radius. In order to studythe topography and roughness of the surface, AFM analysis in contact mode and scanning area of $1 \mu \mathrm{m}^{2}$ were used. Electrochemical corrosion studies of the modified surfaces are done by potentiodynamic method. For these tests a potentionstat model EG\&G applied Princeton $273 \mathrm{~A}$ is used. The corrosion solution was 0.5 molar $\mathrm{H}_{2} \mathrm{SO}_{4}$. The potential was measured by saturated calomel electrode (SCE) as a reference electrode, scanned from $-700 \mathrm{mV}$ versus open circuit potential (OCP) up to approximately $+1500 \mathrm{mV}$ versus OCP at the scan rate of $1 \mathrm{mV} / \mathrm{sec}$. The ends of the scans were selected after considering trans passive behavior in polarization curves. The corrosion

Table 1 Chemical composition of tantalum (wt $\%$ )-method EDX

\begin{tabular}{lll}
\hline Ta & o & C \\
\hline 97.94 & 0.86 & 1.20 \\
\hline
\end{tabular}


potential $\left(\mathrm{E}_{\mathrm{corr}}\right)$ and corrosion current density $\left(\mathrm{i}_{\text {corr }}\right)$ were extracted from potentiodynamic curves with the linear polarization method using corer view software. Surface of the tantalum samples was analyzed by scanning electron microscopy (SEM), with a Sirius SD devise equipped with an energy dispersive X-ray (EDX) analyzer. The average concentration of elements from a plan view of the SEM image with the lowest magnification $(\times 100)$ wear was estimated by EDX analysis.

\section{Result and discussion}

\section{Surface morphology study by AFM}

Figure 2 shows the atomic force microscopy (AFM) images of a $1000 \mathrm{~nm} \times 1000 \mathrm{~nm}$ scan area of the un-implanted samples of (a); the implanted one with argon ion doses of $1 \times 10^{17}(\mathrm{~b}) ; 5 \times 10^{17}(\mathrm{c}) ; 7 \times 10^{18} \mathrm{ions} / \mathrm{cm}^{2}(\mathrm{~d})$; and $1 \times 10^{18}$ ions $/ \mathrm{cm}^{2}$ (e). As shown in Fig. 2b-e, surface texture by ion implantation was directly observed with atomic force microscopy (AFM). There was significant change in areas such as roughness, grain size, its distribution for the un-implanted sample, and samples implanted with argon ions. Surface roughness of the samples underwent a substantial change after bombardment. Figure 3 shows the AFM results through a roughness variation curve. As seen in Fig. 3, Table 3 shows the variation of

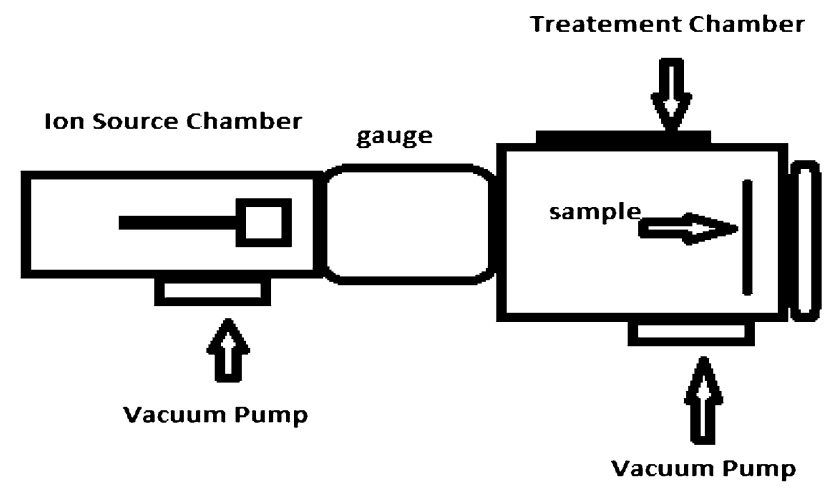

Fig. 1 Diagram of ion implantation system average and root mean square roughness on tantalum. Surface roughness of tantalum increased up to $5 \times 10^{17}$ ions $/ \mathrm{cm}^{2}$ dose and then decreased for the $10 \times 10^{17}$ ions $/ \mathrm{cm}^{2}$ dose.

The former can be explained by the sputtering effect due to the ion bombardment, while the latter may be related to the redistribution of material into valleys by eroding surface roughness peaks and ion bombardment enhancing the surface diffusion mechanism, which occurs at high doses [7]. Another justification for roughness increase in the dose $5 \times 10^{17}$ ions $/ \mathrm{cm}^{2}$ is an increase in surface diffusion of tantalum atoms in the sample surface [8]. It can be clearly seen that the sample surface roughness undergoes a substantial change after bombardment. In the case of unimplanted (Fig. 2) there is a smooth surface whose surface morphology contained many small hillocks, and the root mean-square roughness of the surface has been further measured.

The results of surface roughness, obtained by AFM analysis are given in Table 3 . The initial value of $22.3 \AA$ of the sample before implantation by argon ion implantation on the tantalum with a dose of $1 \times 10^{17}$ ions $/ \mathrm{cm}^{2}$ increased, and since the formation of a comparatively small grain was also observed, the value of surface roughness decreased to $7.25 \AA$ in doses of $10 \times 10^{17} \mathrm{ions} / \mathrm{cm}^{2}$. As shown, the surface roughness has risen by increasing the dose of ion implantation from $1 \times 10^{17}$ to $5 \times 10^{17}$ ions/ $\mathrm{cm}^{2}$, which implies that increasing the dose and rate of deposition leads to larger grain formation on the surface according to incorporation and the integration process.

The increasing surface roughness was confirmed by AFM images' analyses, which exposed the construction of tracks or pathways on the surface. However, by rising the dose to $7 \times 10^{17}$ and $10 \times 10^{17} \mathrm{ions} / \mathrm{cm}^{2}$, almost all pathways and pits were filled uniformly since the surface was bombarded by a constant ion flux and a sufficient dose for deposition. Like the AFM, images revealed the composition of a uniform surface with same dimension grains, and the roughness has been significantly decreased. Therefore, the implanted sample with $10 \times 10^{7}$ ions $/ \mathrm{cm}^{2}$ showed the least value compared with other samples, and the amount of energy in this dose makes the grain composition constant.

Table 2 The process parameters during implantation

\begin{tabular}{lllccc}
\hline Sample $(\#)$ & Ion current $\left(\mu \mathrm{A} / \mathrm{cm}^{2}\right)$ & Dose $\left(\right.$ ions $\left./ \mathrm{cm}^{2}\right)$ & Time $(\mathrm{s})$ & Temperature $\left({ }^{\circ} \mathrm{c}\right)$ & Pressure $\left(\times 10^{-6}\right)$ Torr \\
\hline 0 & - & Unimplanted & - & - & - \\
1 & 40 & $1 \times 10^{17}$ & 470 & 100 & 3 \\
2 & 40 & $5 \times 10^{17}$ & 700 & 100 & 3 \\
3 & 40 & $7 \times 10^{17}$ & 1120 & 100 & 3 \\
4 & 40 & $10 \times 10^{17}$ & 1550 & 100 & 3 \\
\hline
\end{tabular}




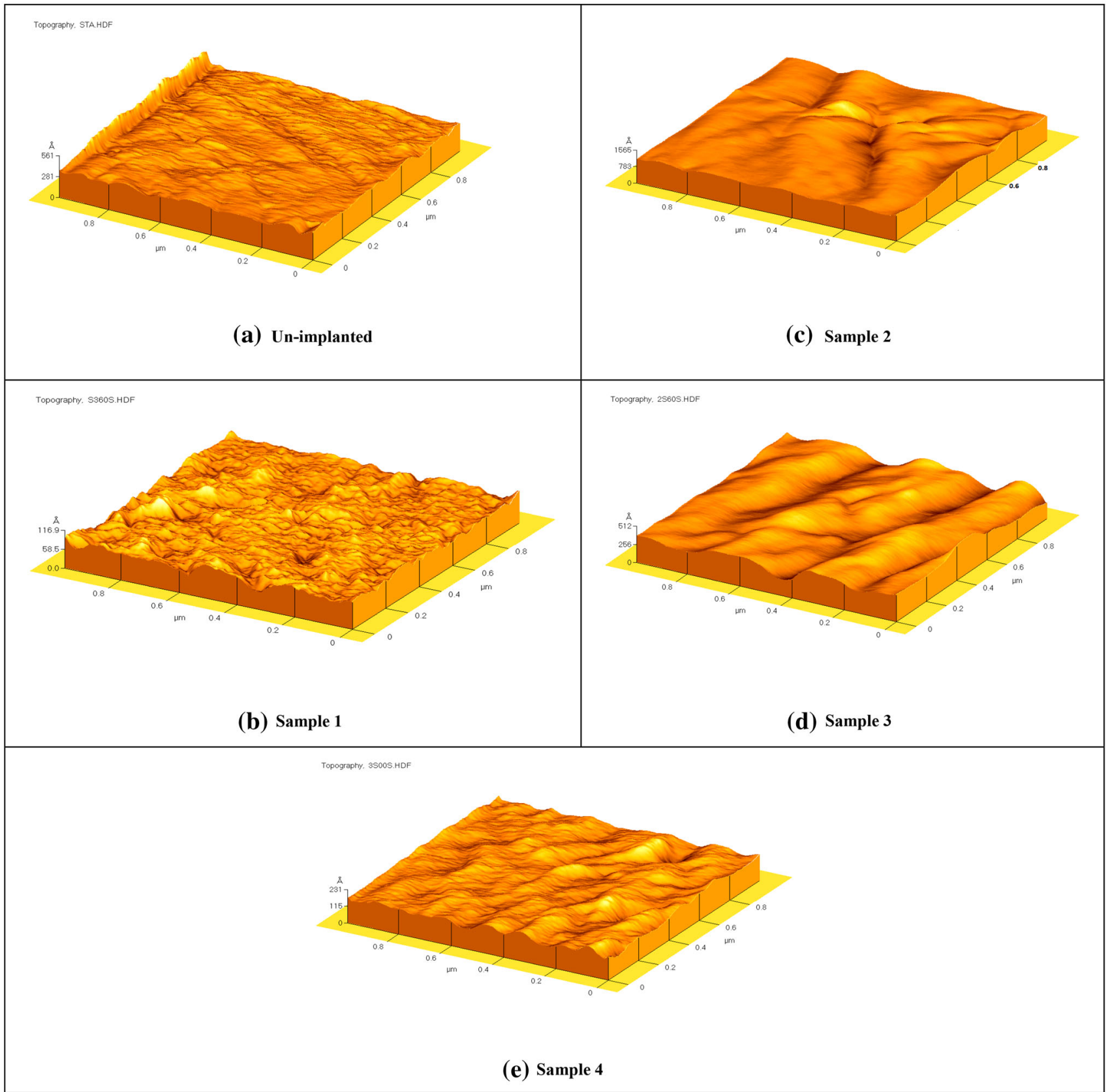

Fig. 2 Three-dimensional AFM images of sample surfaces a unimplanted, b dose $1 \times 10^{17}$ ions $/ \mathrm{cm}^{2}$, c dose $5 \times 10^{17}$ ions $/ \mathrm{cm}^{2}$, d dose $7 \times 10^{17}$ ions $/ \mathrm{cm}^{2}$, e dose $10 \times 10^{17}$ ions $/ \mathrm{cm}^{2}$

\section{Corrosion test}

Figure 4 shows the potentiodynamic findings by electrochemical analysis in the implanted and unimplanted samples in different doses. According to Figs. 5 and 6, the corrosion current and potential are, respectively, recognized as corrosion resistance in all implanted samples. The corrosion current has minimum value in implanted samples compared to the unimplanted ones.
Figure 5 shows the differences of corrosion current density ( $\mathrm{i}_{\text {corr }}$ ) of the implanted tantalum samples in terms of argon implantation doses. This curve shows that the maximum and minimum corrosion current density happens at samples implanted with doses of $5 \times 10^{17}$ and $10 \times 10^{17}$ ions $/ \mathrm{cm}^{2}$, respectively. In the meantime, no substantial variation in passivation current has been observed even though the corrosion potential increased significantly. As can be observed, corrosion current density 


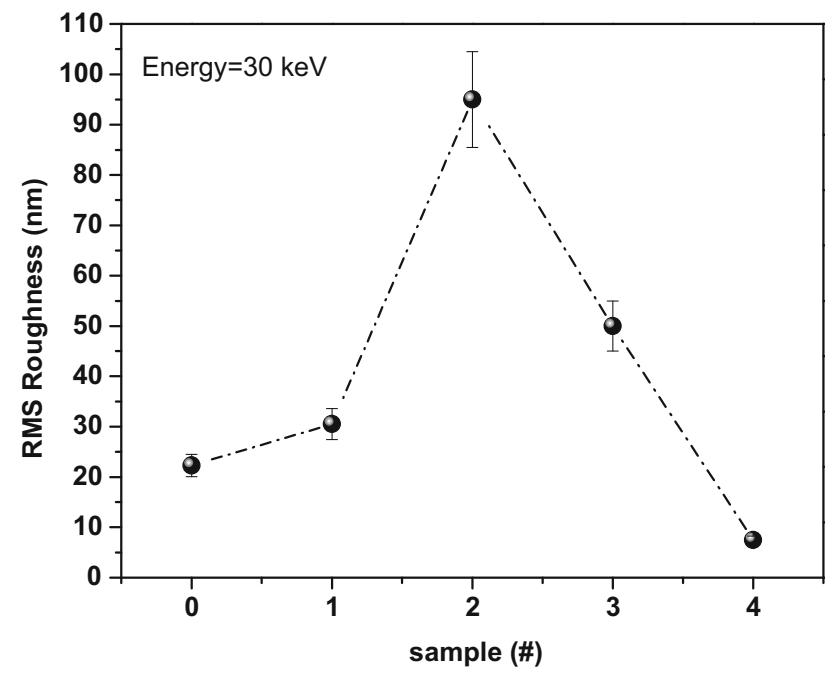

Fig. 3 Roughness variation of tantalum surface to argon ion implantation increase

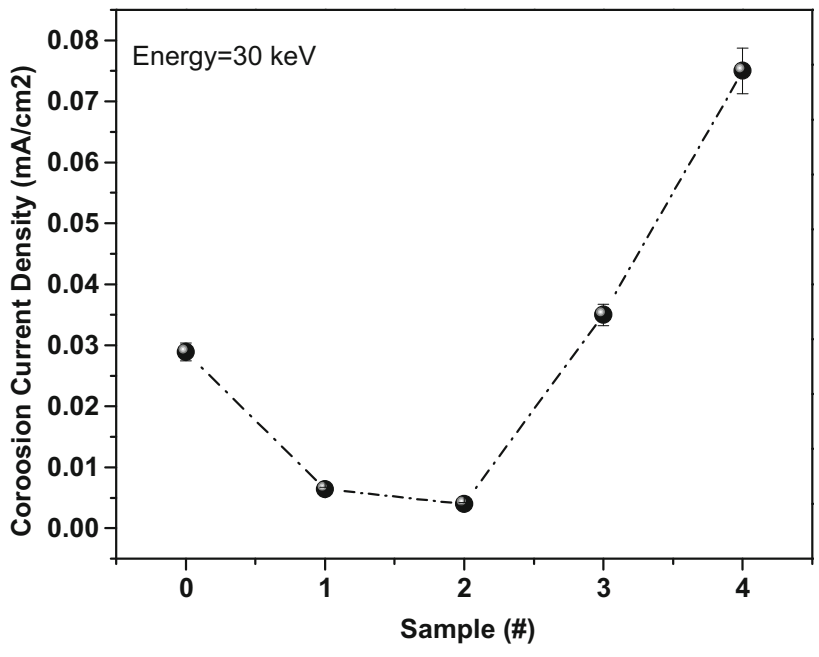

Fig. 5 Corrosion current densities variation because of the ion implanted in the different doses
Table 3 variation of average roughness and root mean square roughness

\begin{tabular}{llll}
\hline Sample $(\#)$ & Dose $\left(\mathrm{ion} / \mathrm{cm}^{2}\right)$ & RMS roughness $(\AA)$ & Average roughness $(\AA)$ \\
\hline Unimplanted & 0 & 22.3 & 15.7 \\
1 & $1 \times 10^{17}$ & 30.52 & 5.64 \\
2 & $5 \times 10^{17}$ & 95.3 & 69.7 \\
3 & $7 \times 10^{17}$ & 50.3 & 41.3 \\
4 & $10 \times 10^{17}$ & 7.52 & 29.7 \\
\hline
\end{tabular}

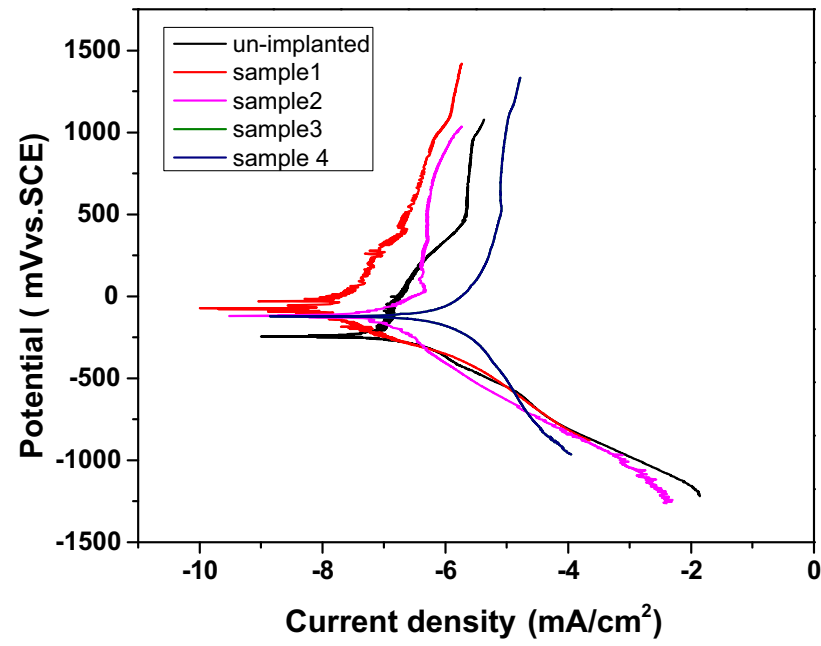

Fig. 4 Polarization curves of unimplanted and implanted tantalum samples

$\left(\mathrm{i}_{\text {corr }}\right)$ decreases initially at $5 \times 10^{17}$ ions $/ \mathrm{cm}^{2}$ and then increases. Figure 6 shows the values of the corrosion potential for unimplanted and implanted samples. In addition, it shows that argon ion implantation in tantalum increases the corrosion potential of the implanted samples at doses of $1 \times 10^{17}$ ions $/ \mathrm{cm}^{2}$. This tendency continues up to the $5 \times 10^{17}$ ions $/ \mathrm{cm}^{2}$ dose, but at the dose of

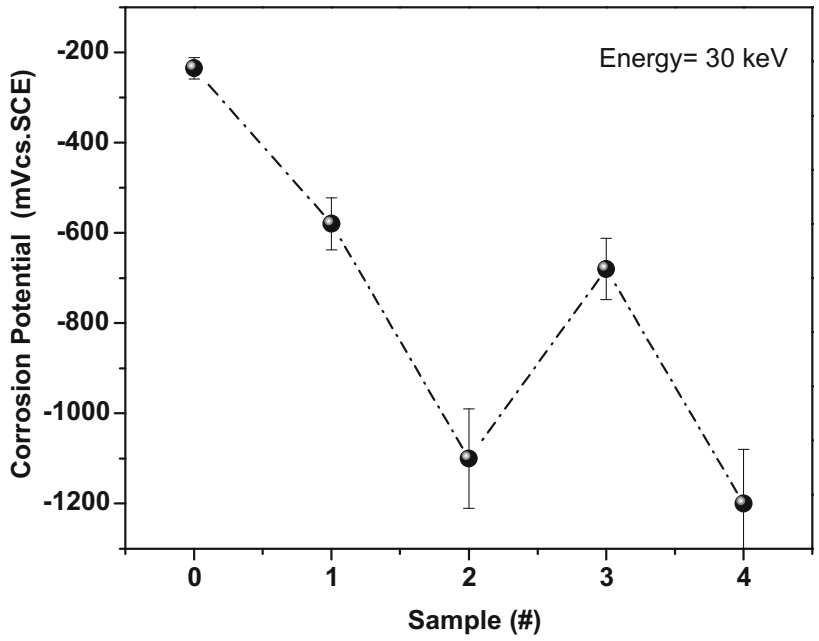

Fig. 6 Corrosion potential variations because of ion implantation in different doses

$7 \times 10^{17}$ ions $/ \mathrm{cm}^{2}$, the corrosion potential slightly decreases. Moreover, corrosion potential in implanted samples exposed maximum value to the unimplanted samples. According to the AFM images, the reason of these reverse findings can be explained by inadequate ion energy bombardment on the surface concerning the formation of cracks and pores in grain bounders. Therefore, increasing 
the roughness of the surface in grain boundaries increases the tendency to corrosion compared to other conditions. Furthermore, based on the obtained findings with corrosion, current and potential curve, all implanted samples exposed suitable performance for corrosion, which implies that the surface corrosion resistance has improved by argon ion implantation.

\section{Scanning electron microscopy (SEM)}

Scanning electron microscopy (SEM) images of samples were applied to show the formation of thick corrosion products on a sample surface implanted by various argon doses (Fig. 7). The creation of the corrosion products can be observed on the surface of the sample with $1 \times 10^{17}$ ions/ $\mathrm{cm}^{2}$ dose (Fig. 7b). Argon doses in ion beam processes at $1 \times 10^{17}$ ions $/ \mathrm{cm}^{2}$ can not only create a protective layer, but also damage the surface of the tantalum due to the high collision rate of ions with the surface tantalum. In a dose of $1 \times 10^{17}$ ions $/ \mathrm{cm}^{2}$, surface defects increase substantially and, therefore, corrosion rate increases accordingly. Corrosion rate decreases by the increase of dose at $5 \times 10^{17}$ ions/ $\mathrm{cm}^{2}$, but local pitting corrosion is clearly observed on the surfaces of the samples (Fig. 7c). Maximum effect of corrosion occurred in the implanted sample with a dose of $7 \times 10^{17}$ ions $/ \mathrm{cm}^{2}$, and minimum corrosion was detected in the sample with a dose of $5 \times 10^{17}$ ions $/ \mathrm{cm}^{2}$. It can be concluded that not only the implanted layer on the surface is not resistive in the low doses $\left(1 \times 10^{17}\right.$ ions $\left./ \mathrm{cm}^{2}\right)$ of argon, but also the initial surface is damaged due to high collision rate between ionized atoms, and this cannot protect the surface against corrosion.

Corrosion rate decreases by increasing argon dose at $5 \times 10^{17}$ ions $/ \mathrm{cm}^{2}$, but local pitting corrosion is clearly observed on the surfaces of the tantalum samples (Fig. 7c). It is also worth mentioning that the conditions for corrosion have improved according to corrosion morphology and with regard to pit formation. Higher surface roughness leads to an increase of effective surface in contact with the corrosive agent increasing the corrosion attack. With regard to roughness variation in argon implantation, at the fluency of $5 \times 10^{17}$ ions $/ \mathrm{cm}^{2}$, a maximum of roughness is detected which is probably due to difference of surface roughness in two cases.
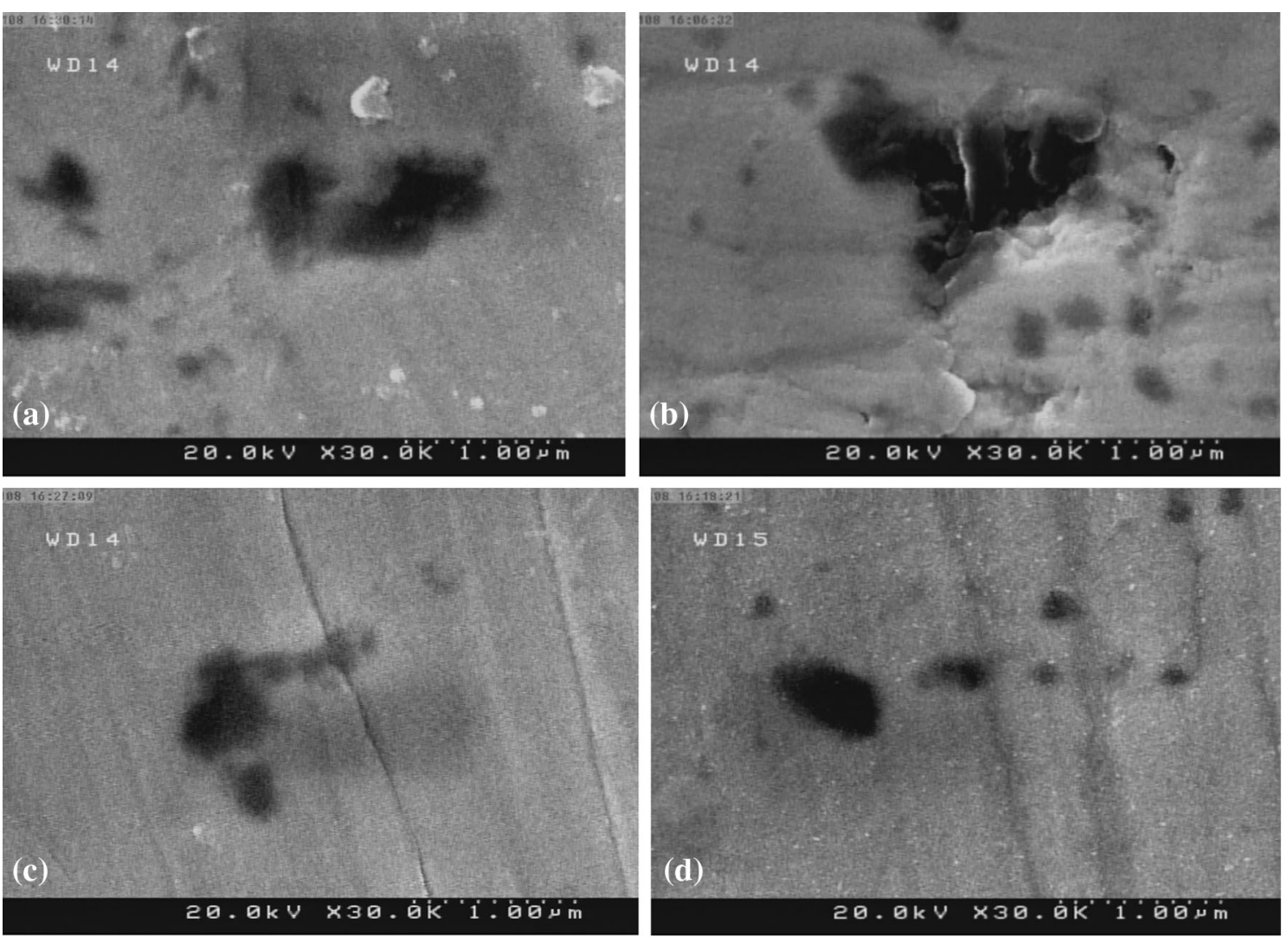

Fig. 7 SEM images of implanted samples after corrosion test with argon dose a unimplanted, b $1 \times 10^{17}$ ions $/ \mathrm{cm}^{2}$, and $\mathbf{c} 5 \times 10^{17}$ ions/cm ${ }^{2}$, d $7 \times 10^{17}$ ions $/ \mathrm{cm}^{2}$ 


\section{Conclusion}

In this paper, the influences of $30 \mathrm{keV}$ argon ion bombardments on corrosion behavior of the Tantalum samples have been discussed by analyzing the obtained data of AFM. The roughness and corrosion potential curves clearly indicate that corrosion potential variations caused by argon ion implantation are inversely proportional to surface roughness. Hence, according to scanning electron microscopy and corrosion results, this sample $\left(5 \times 10^{17}\right.$ ions/ $\mathrm{cm}^{2}$ ) presents the highest corrosion resistance against the $\mathrm{H}_{2} \mathrm{SO}_{4}$ corroding media. Corrosion current variations in implanted sample indicate an optimal dose at $5 \times 10^{17}$ ions $/ \mathrm{cm}^{2}$ in which the corrosion resistivity is 12 percent in the higher than un-implanted sample. Furthermore, it can be realized that the best resistance against corrosion can be achieved by bombarding with argon.

Acknowledgements In this research, "The Effects of Argon Ion Bombardment on the Corrosion Resistance of Tantalum" is supported by Department of Physics West Tehran Branch, Islamic Azad University, Tehran, Iran.

Open Access This article is distributed under the terms of the Creative Commons Attribution 4.0 International License (http://crea tivecommons.org/licenses/by/4.0/), which permits unrestricted use, distribution, and reproduction in any medium, provided you give appropriate credit to the original author(s) and the source, provide a link to the Creative Commons license, and indicate if changes were made.

\section{References}

1. Shen, L.R., Wang, K., Tie, J., Tong, H.H., Chen, Q.C., Tang, D.L.: Sur. Coat. Tech. 196, 349 (2005)
2. Liu, Y.Z., Zu, X.T., Caol Wang, J., Li, C., Haung, X.Q.: Nucl. Instr. Meth. Phys. Res. B 237, 543 (2005)

3. Saritas, S., Procter, R.P.M., Grant, W.A.: Sci. Eng. A 115, 307 (1989)

4. Leiato, E., Silva, R.A., Barbosa, M.A.: J. Mater. Med. 8, 365 (1997)

5. Devax, R., Vouagner, D., Becdeliver, A.M.: Corros. Sci. 36, 171 (1998)

6. Townsend, J.J.: Contemp. Phys. 27, 241 (1987)

7. Patila, S.S., Fernandesa, R.P., Patela, N.K., Rayjadab, P.A., Raoleb, P.M., Kotharia, D.C.: Surf. Coat. Technol. 196, 284 (2005)

8. Budzynskia, P., Filiksb, J., Ukowskic, P., Kiszczakb, Z., Walczaka, K.M.: Vacuum 78, 658 (2005)

9. De, A.K., Speer, J.G., Matlock, D.K., Murdock, D.C., Mataya, M.C., Comstock, R.J.: Metall. Mater. Trans. A 37, 1875 (2006)

10. Kowalski, Z.W., Wilk, J., Martan, J.: Vacuum 83, 208 (2009)

11. Belus, V.A., Nosov, G.I.: In: IEEE Proceedings of the 18th International Symposium on discharges and electrical insulation in vacuum, Eindhoven, 634, (1998)

12. McCafferty, E., Hubler, G.K., Natishan, P.M., Moore, P.G., Kant, R.A., Sartwell, R.D.: Mater. Sci. Eng. 86, 1 (1987)

13. Natishan, P.M., McCafferty, E., Hubler, G.K.: J. Electrochem. Sot. 135, 321 (1988)

14. McCafferty, E., Natishan, P.M., Hubler, G.K.: Corros. Sci. 30, 209 (1990)

15. McCafferty, E., Hubler, G.K.: J. Electrochem. Sot. 125, 1892 (1978)

16. Clayton, C.R., Wang, Y.F., Hubler, G.K.: In: Froment, M. (ed.). Passivity of metals and semiconductors, p. 305. Elsevier, Amsterdam (1983)

17. Hubler, G.K., Trzaskoma, P.P., McCafferty, E., Singer, I.L.: In: Ion implantation into metals, p. 24. (1982) 